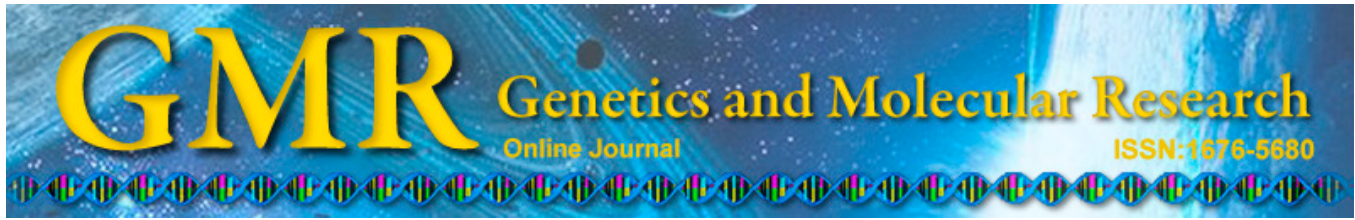

\title{
Assessment of genetic diversity of bermudagrass germplasm from southwest China and Africa by using AFLP markers
}

\author{
Y. Ling', L.K. Huang ${ }^{2}$, X.Q. Zhang ${ }^{2}$, X. Ma ${ }^{2}$, W. Liu' ${ }^{2}$ S.Y. Chen ${ }^{2}$ and \\ H.D. Yan $^{1}$ \\ ${ }^{1}$ Institute for New Socialist Countryside Development, Ya'an, Sichuan, China \\ ${ }^{2}$ Department of Grassland, Sichuan Agricultural University, Ya'an, Sichuan, China \\ Corresponding author: X.Q. Zhang \\ E-mail: zhangxq@sicau.edu.cn
}

Genet. Mol. Res. 14 (1): 1748-1756 (2015)

Received January 27, 2014

Accepted June 30, 2014

Published March 13, 2015

DOI http://dx.doi.org/10.4238/2015.March.13.1

\begin{abstract}
Cynodon dactylon (L.) Pers. var. dactylon (common bermudagrass) is widely distributed geographically between approximately $45^{\circ} \mathrm{N}$ and $45^{\circ} \mathrm{S}$ latitude, penetrating to approximately $53^{\circ} \mathrm{N}$ latitude in Europe. The extensive variation of morphological and adaptive characteristics of the taxon has been substantially documented, but information is lacking on DNA molecular variation in geographically disparate forms. The genetic diversity of 51 wild accessions of bermudagrass from southwest China (Sichuan, Chongqing, Yunnan, Guizhou, and Tibet) and 8 African bermudagrass was analyzed using amplified fragment length polymorphism molecular markers. A total of 670 polymorphic bands were detected with 11 primer combinations, of which $663(98.74 \%)$ bands were found to be polymorphic. The genetic similarity among the accessions ranged from 0.64-0.96 with an average of 0.78 . All 59 wild accessions were clustered into 5 ecogeographic groups, and nearly all accessions from the same area were classified into the same group and were found to be associated with their geographical distributions. Therefore, complex geographical and
\end{abstract}


ecological environments are important factors for the genetic structure and geographical distribution of C. dactylon.

Key words: AFLP marker; Bermudagrass; Genetic structure

\section{INTRODUCTION}

Cynodon dactylon (L.) Pers. var. dactylon (common bermudagrass), which shows widespread distribution in warmer parts of the world, is used as livestock herbage and turf and is the most important member of the genus Cynodon. It originates from Africa and is widely distributed in South America, Africa, Europe, and South Asia (Langdon, 1954). In China, bermudagrass is mainly distributed along the southern region of the Yellow River Valley (Zhang et al., 2003).

In the natural growth condition, $C$. dactylon var. dactylon has a seed-setting rate ranging 2.8-43.2, whereas the rate of self-pollination is only 0.01-8.09 (Burton, 1965), suggesting it has a higher genetic variation in its natural population. Therefore, the natural genetic variation of bermudagrass is very significant (Richardson et al., 1978). Recent years, with the deterioration of ecological environment, plant populations have rapidly decreased, which could result in lost for several excellent genes.

Polymerase chain reaction (PCR)-based DNA fingerprinting techniques based on the analysis of information-rich nucleic acid molecules have been used to study genetic diversity, relatedness, phylogeny, and identifying off-types of cultivars in turfgrass (Caetano-Anollés, 1998). A number of researchers have employed randomly amplified polymorphic DNA (Iqbal et al., 2008; Zhang et al., 2011; Huo et al., 2013) and DNA amplified fingerprinting procedures (Caetano-Anollés et al., 1995, 1997; Karaca et al., 2002; Zhang et al., 2013). Recently, the amplified fragment length polymorphism (AFLP) DNA method (Vos et al., 1995) has been used to detect genetic diversity among forage bermudagrass cultivars (Karaca et al., 2002), to quantify the genetic variation of Cynodon transvaalensis and its relatedness to hexaploid $C$. dactylon var. dactylon (Wu et al., 2005), and to detect genetic analyses of Chinese C. dactylon var. dactylon accessions (Wu et al., 2006). A large number of wild C. dactylon var. dactylon germplasm grow in southwest China; however, there have been few studies examining the genetic diversity of wild C. dactylon var. dactylon in this region. In this study, AFLP molecular markers were used to analyze and evaluate the genetic diversity and relationship of $C$. dactylon var. dactylon in southwest of China and Africa. Our data provide methods and a theoretical basis for further gathering, collection, identification, relationship analysis, and breeding of wild C. dactylon var. dactylon.

\section{MATERIAL AND METHODS}

\section{Plant material}

Fifty-nine wild accessions of $C$. dactylon var. dactylon were collected from 5 provinces in southwest China (Sichuan, Chongqing, Yunnan, Guizhou, and Tibet) and Africa (Table 1). A healthy growing branch was collected from each sample, and a wet towel wrapped was wrapped around the branch for transport to the test base before preparing cuttings for the reproduction of clones. 
Table 1. Wild Cynodon dactylon var. dactylon accessions tested in this study.

\begin{tabular}{|c|c|c|c|c|}
\hline Order & Accession number & Origin & Habit & Altitude (m) \\
\hline 1 & Sau9933 & Wenchuan, Sichuan & Roadside & 1210 \\
\hline 2 & Sau9935 & Maoxian, Sichuan & Wasteland & 1480 \\
\hline 3 & Sau9936 & Maoxian, Sichuan & Wasteland & 1460 \\
\hline 4 & Sau02011 & Wenchuan, Sichuan & Roadside & 1310 \\
\hline 5 & Sau02012 & Jinchuan, Sichuan & Roadside & 2150 \\
\hline 6 & Sau02015 & Jinchuan, Sichuan & Roadside & 1310 \\
\hline 7 & Sau02004 & Leibo, Sichuan & Flood land & 1200 \\
\hline 8 & Sau02005 & Huidong, Sichuan & Roadside & - \\
\hline 9 & Sau02006 & Ningnan, Sichuan & Roadside & - \\
\hline 10 & Sau0085 & Xichang, Sichuan & Flood land & 1380 \\
\hline 11 & Sau02053 & Xichang,Sichuan & Flood land & 1380 \\
\hline 12 & Sau0088 & Mianning, Sichuan & Field ridge & 1774 \\
\hline 13 & Sau02033 & Yuexi, Sichuan & Roadside & - \\
\hline 14 & Sau0099 & Panzhihua, Sichuan & Roadside & 1100 \\
\hline 15 & Sau0098 & Panzhihua, Sichuan & Woodland & 1120 \\
\hline 16 & Ly97017 & Panzhihua, Sichuan & Grassland & 1200 \\
\hline 17 & Sau02028 & Miyi, Sichuan & Hillside & 1620 \\
\hline 18 & Sau0095 & Yanbian, Sichuan & Field ridge & 1150 \\
\hline 19 & Sau9918 & Ya'an, Sichuan & Grassland & 600 \\
\hline 20 & Sau02055 & Baoxing, Sichuan & Hillside & 1010 \\
\hline 21 & Sau02060 & Yingjing, Sichuan & Roadside & 720 \\
\hline 22 & Sau02061 & Tianquan, Sichuan & Riverside & 740 \\
\hline 23 & Sau02064 & Lushan, Sichuan & Hillside & 630 \\
\hline 24 & Sau02065 & Lushan, Sichuan & Riverside & 685 \\
\hline 25 & Sau9927 & Yibin, Sichuan & Flood land & 240 \\
\hline 26 & Sau9922 & Yibin, Sichuan & Riverside & 255 \\
\hline 27 & Sau9931 & Yibin, Sichuan & Flood land & 245 \\
\hline 28 & Sau9924 & Yibin, Sichuan & Roadside & 340 \\
\hline 29 & Sau9926 & Yibin, Sichuan & Wasteland & 260 \\
\hline 30 & Sau02041 & Yibin, Sichuan & Riverside & 250 \\
\hline 31 & Sau02042 & Yibin, Sichuan & Riverside & 250 \\
\hline 32 & Sau02045 & Liangping, Chongqing & Riverside & 400 \\
\hline 33 & Sau02046 & Liangping, Chongqing & Roadside & 380 \\
\hline 34 & Sau9942 & Changshou, Chongqing & Woodland & 305 \\
\hline 35 & Sau9945 & Changshou, Chongqing & Flood land & 140 \\
\hline 36 & Sau9947 & Jialing, Chongqing & Woodland & 230 \\
\hline 37 & Sau02050 & Wanzhou, Chongqing & Shipside & 150 \\
\hline 38 & Sau02048 & Wanzhou, Chongqing & Roadside & 490 \\
\hline 39 & Sau02019 & Libo, Guizhou & Flood land & 370 \\
\hline 40 & Sau02020 & Libo, Guizhou & Flood land & 360 \\
\hline 41 & Sau02022 & Dushan, Guizhou & Roadside & 950 \\
\hline 42 & Sau02023 & Dushan, Guizhou & Field ridge & 970 \\
\hline 43 & Sau02024 & Dushan, Guizhou & Roadside & 810 \\
\hline 44 & Sau02025 & Dushan, Guizhou & Roadside & 890 \\
\hline 45 & Sau03001 & Bayi, Tibet & Garden & 3080 \\
\hline 46 & Sau03002 & Chayu, Tibet & Roadside & 2550 \\
\hline 47 & Sau03003 & Chayu, Tibet & Roadside & 2460 \\
\hline 48 & Sau02026 & Xiaoshao, Yunnan & Groove & 1900 \\
\hline 49 & Sau02027 & Xiaoshao, Yunnan & Roadside & 1910 \\
\hline 50 & Ly98010 & Kunming, Yunnan & Roadside & 1720 \\
\hline 51 & Sau02054 & Qiaojia, Yunnan & Roadside & 841 \\
\hline 52 & 19712D & Africa & Roadside & - \\
\hline 53 & $13318 \mathrm{D}$ & Africa & Roadside & - \\
\hline 54 & $15014 \mathrm{D}$ & Africa & Roadside & - \\
\hline 55 & 16717D & East Africa & Roadside & - \\
\hline 56 & $16741 \mathrm{D}$ & Africa & Roadside & - \\
\hline 57 & 19710D & Africa & Roadside & - \\
\hline 58 & $15725 \mathrm{D}$ & Africa & Roadside & - \\
\hline 59 & $16708 \mathrm{D}$ & East Africa & Roadside & - \\
\hline
\end{tabular}

\section{DNA extraction and PCR amplification}

DNA samples were isolated from fresh leaf tissues of the C. dactylon var. dactylon 
plants with DNeasy plant mini kit from QIAGEN, Inc. (Hilden, Germany). The AFLP analysis was performed as described by Vos et al. (1995) with minor modifications (Bai et al., 1999). The AFLP procedure followed Wu et al. (2005). Primer sequences are shown in Table 2.

Table 2. Primer sequences used in AFLP analyses of Cynodon dactylon var. dactylon.

\begin{tabular}{llll}
\hline EcoRI & Sequences $\left(5^{\prime}-3^{\prime}\right)$ & Mse & Sequences $\left(5^{\prime}-3^{\prime}\right)$ \\
\hline E-AAC & GACTGCGTACCAATCAAC & M-CTC & GATGAGTCCTGAGTAACTC \\
E-ACA & GACTGCGTACCAATTCACA & M-CTG & GATGAGTCCTGAGTAACTG \\
E-ACT & GACTGCGTACCAATTCACT & M-CAC & GATGAGTCCTGAGTAACAC \\
E-ACT & GACTGCGTACCAATTCACT & M-CTA & GATGAGTCCTGAGTAACTA \\
E-ACC & GACTGCGTACCAATTCACC & M-CTA & GATGAGTCCTGAGTAACAT \\
E-ACG & GACTGCGTACCAATTCACG & M-CTG & GATGATCCTGAGTAACTA \\
E-ACG & GACTGCGTACCAATTCACG & M-CTT & GATGAGTCCTGAGTAACTG \\
E-ACG & GACTGCGTACCAATTCACG & M-CTG & GATGAGTCCTGAGTAACTG \\
E-AGC & GACTGCGTACCAATTCAGC & M-CAC & GATGAGTCCTGAGTAACAC \\
E-ACG & GACTGCGTACCAATTCACG & M-CTT & GATGAGTCCTGAGTAACTT \\
E-ACA & GACTGCGTACCAATTCACA &
\end{tabular}

\section{Data analysis}

Unequivocally and consistently reproducible amplified AFLP bands were scored as present (1) or absent (0). Smeared and weak bands were excluded. Fragments of the same molecular weight were considered to be the same locus.

An unweighted pair-group method using arithmetic average (UPGMA) dendrogram was constructed based on the matrix of Nei's unbiased genetic distance (Nei and Li, 1979) and bootstrapping was conducted with 1000 replicates using the program TFPGA (Miller, 1999). The genetic similarity index was calculated as GS $=2 N i j /(N i+N j)$, where $N i$ was the bands appearing in the material (i). $N j$ indicated the bands appearing in the material (j). Nij were bands common in material (i) and material (j).

Principal components analysis on the genetic similarity index was conducted according to the first principal component and the second principal component, resulting in variation, and a 3-dimensional scatter plot was constructed.

\section{RESULTS}

\section{AFLP polymorphism}

Eleven AFLP selective amplification primer combinations produced a total of 670 bands among the 59 C. dactylon var. dactylon genotypes, with an average of 60.91 bands per primer combination (Table 3). Of the 670 bands scored, 663 (98.74\%) were polymorphic, with an average of 60.27 polymorphic bands per primer combination. The primer combinations E-AGC-M-CTG and E-ACT-M-CAC amplified the largest (76) and smallest (39) numbers of total bands and polymorphic bands per gel, respectively (Table 3). Non-repeatable bands mainly included faint bands that showed up in some PCRs, but not in others. These results are consistent with previous reports regarding the reproducibility of AFLP markers (Zhang et al., 1999; Mian et al., 2002) and further confirm that the AFLP technique generates highly reproducible DNA profiles for $C$. dactylon var. dactylon. The size of polymorphic bands ranged from 100-500 base pairs. An AFLP gel with PCR products using primer combination E-AGC$\mathrm{M}-\mathrm{CTG}$ is shown in Figure 1. 
Table 3. Amplification results from 10 primer combinations.

\begin{tabular}{lccc}
\hline Primer pairs & Total No. of polymorphic bands & No. of polymorphic bands & Percentage of polymorphic bands (\%) \\
\hline E-AAC-M-CTC & 42.00 & 40.00 & 95.24 \\
E-ACA-M-CTG & 64.00 & 63.00 & 98.44 \\
E-ACT-M-CAC & 39.00 & 38.00 & 97.44 \\
E-ACT-M-CTA & 53.00 & 52.00 & 98.11 \\
E-ACC-M-CAT & 67.00 & 66.00 & 98.51 \\
E-ACG-M-CTA & 67.00 & 67.00 & 100.00 \\
E-ACG-M-CTG & 62.00 & 61.00 & 98.39 \\
E-ACG-M-CTT & 62.00 & 62.00 & 100.00 \\
E-AGC-M-CTG & 76.00 & 76.00 & 100.00 \\
E-ACG-M-CAC & 76.00 & 76.00 & 100.00 \\
E-ACA-M-CTT & 62.00 & 62.00 & 100.00 \\
Total & 670.00 & 663.00 & 98.74 \\
Average & 60.91 & 60.27 &
\end{tabular}

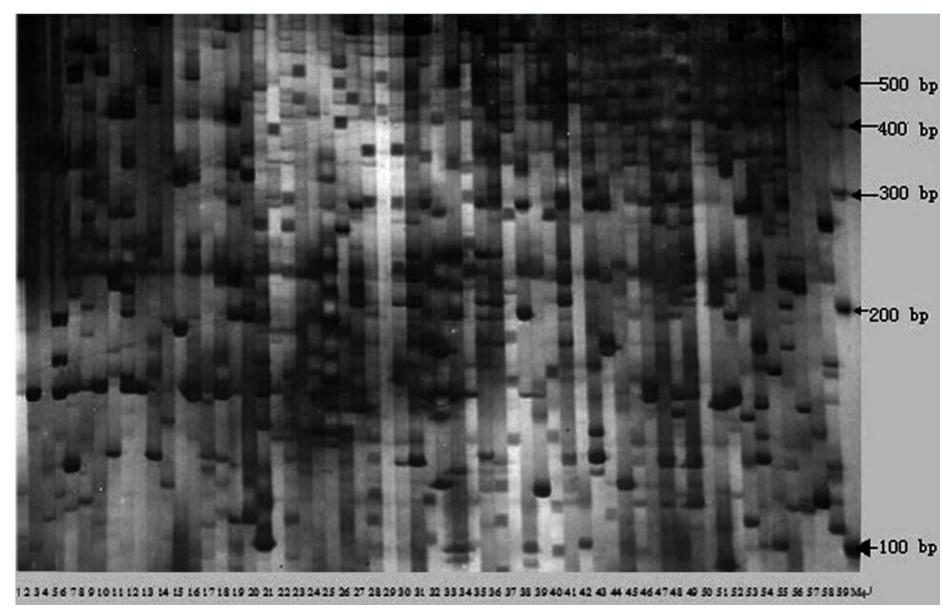

Figure 1. Fingerprinting patterns amplified using the primer combination E-AGC $\sim$ M-CTG. Lanes 1-59= same as the order shown in Table 1.

\section{Genetic similarity analysis}

Nei-Li genetic similarity coefficients were calculated using the NTSYS-pc2.10t software and a dendrogram was constructed using UPGMA. We observed significant differences in genetic diversity between the tested materials. The Nei's genetic similarity coefficient of the tested accessions ranged from 0.64-0.96. The average Nei's coefficient was 0.78 , and the transformer was 0.32 . The similarity coefficient matrix revealed that $C$. dactylon var. dactylon collected from Xiaosao, Yunnan (Sau02026), and East Africa (16717D) had both the lowest genetic similarity coefficient and the largest genetic distance, while the 2 C. dactylon var. dactylon (Sau02023 and Sau02024) samples collected from Dushan and Guizhou showed the opposite results.

\section{Cluster analysis}

Based on the genetic similarity coefficient, 59 materials were tested using UPGMA cluster analysis (Figure 2). UPGMA cluster analysis indicated that when GS $=0.81,59$ wild 
accessions were clustered into 5 groups. Cluster I contained the 31 materials from Sichuan and 2 materials (Sau9945 and Sau02050) from Chongqing. In cluster I, the 2 materials (Sau9945 and Sau02050) from Chongqing were clustered together first and the 31 materials from Sichuan were clustered into 1 subgroup. Cluster II contained the 2 materials (Sau02019 and Sau02020) from Guizhou and 5 materials from Chongqing. In cluster II, the 5 materials from Guizhou were clustered first, as they were the most closely related. Cluster III contained 4 materials from Yunnan and 4 materials from Guizhou. Three materials from Tibet composed cluster IV. The 8 materials from Africa composed cluster V.

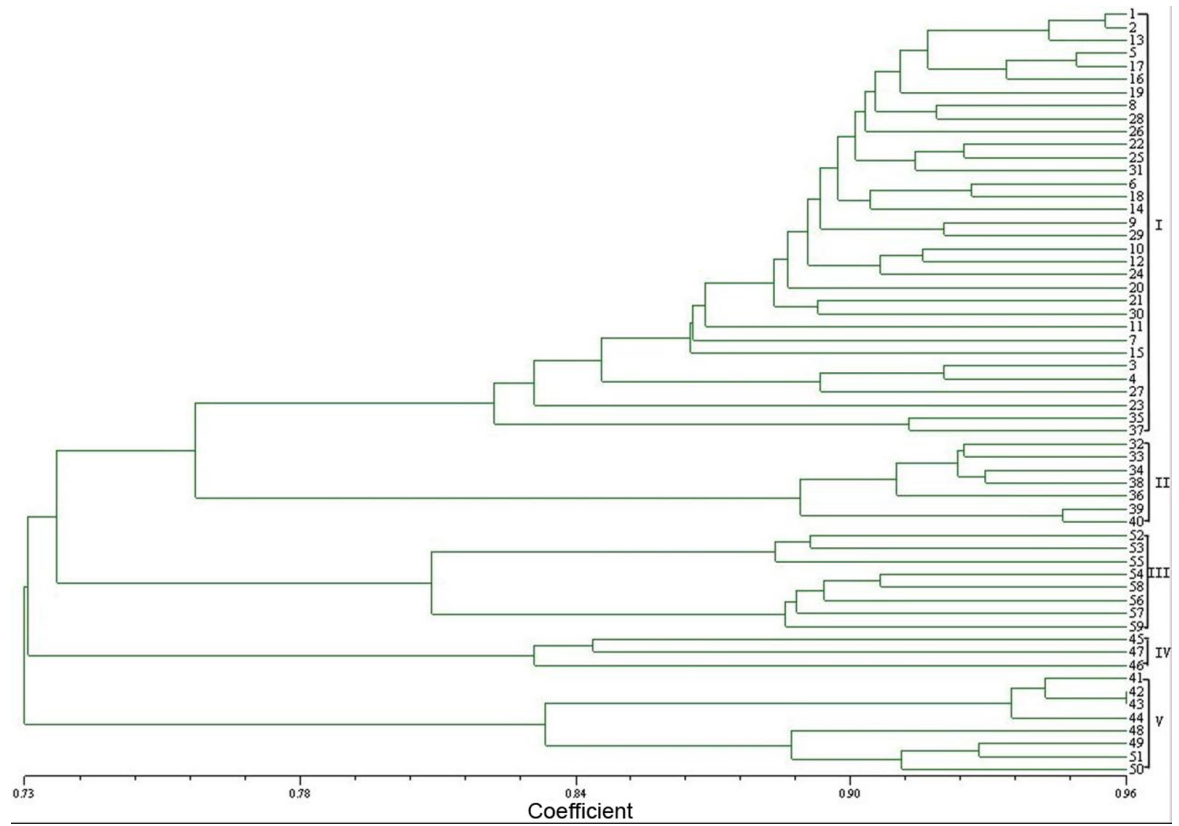

Figure 2. UPGMA dendrogram for Cynodon dactylon var. dactylon based on Nei-Li's genetic similarity coefficients.

\section{Principal components analysis of $C$. dactylon var. dactylon}

The genetic similarity index was evaluated using principal components analysis. Each point on the scatter diagram represents a material. The location of the material more directly reflects the genetic structure and genetic relationship of provenances. The proximity of the locations indicates a closer genetic distance; otherwise, a larger genetic distance was assumed. The 3 principal components showed that the genetic distances were 17.02, 16.68, and 16.21\%, respectively.

Fifty-nine tested materials were used to construct the 3-dimensional scatter plot (Figure 3). These materials were considered to be a class, for which each location was close to the other. As a result, the 59 materials tested were roughly divided into 5 eco-geographical taxa. Figure 3 shows that the materials from China and the materials from Africa had a large distance, indicating that the genetic distance was also large. The materials from China showed significant genetic distance, while most materials from the same area in China showed lower differences. These results were consistent with those determined based on clustering. 


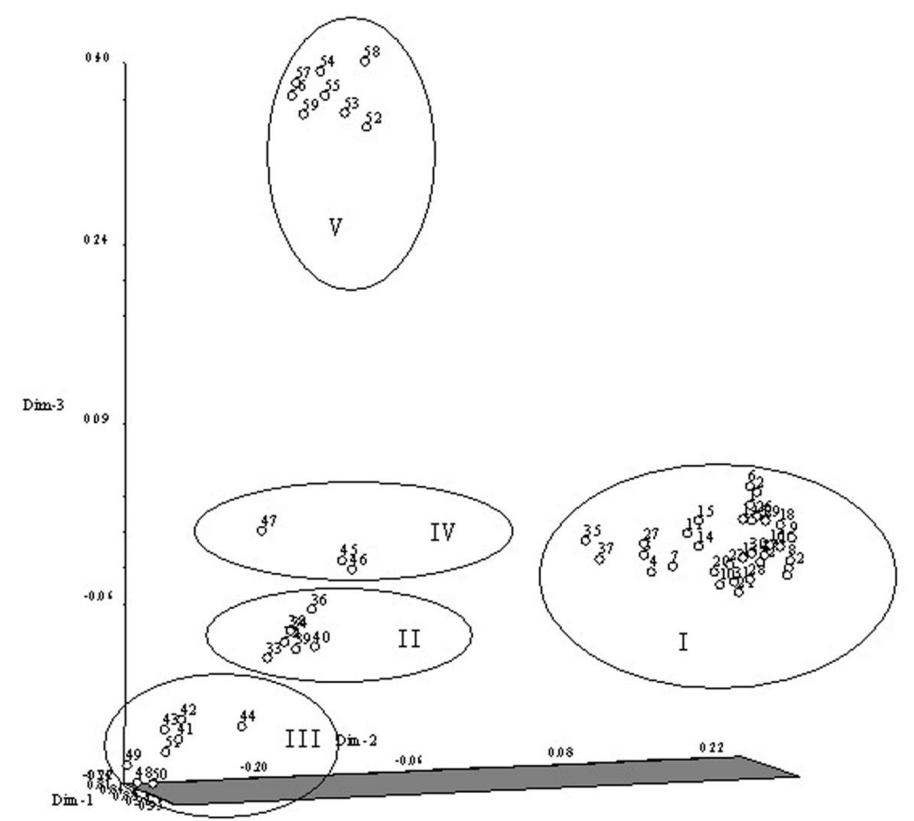

Figure 3. Principal component analysis based on AFLP patterns in Cynodon dactylon var. dactylon.

\section{DISCUSSION}

In this study, the extent of genetic relatedness among 59 tested materials was determined by the estimation of genetic distance measures, with clustering determined by UPGMA and principal component analysis. The results showed that the percentage of polymorphic bands was an average of $98.74 \%$. Therefore, AFLP is a high-resolution method that can be used for detecting variation and polymorphisms among and within accessions of $C$. dactylon var. dactylon.

The relationship between genetic distance and geographical environment of species is widely examined based on the genetics of a plant population. Most studies have suggested that there is some correlation between the genes in species and the geographic distribution of the germplasm (Wilson et al., 2001; Liu, 2007, 2008; Yi et al., 2008). In this study, we observed a strong correlation between materials' genetic relationships and growing locations, which is consistent with the results of Wilson et al. (2001). In general, materials from the same eco-geographical environment can be clustered into 1 group. For example, the materials from Africa could be clearly separated from the materials from China because of the unique tropical desert climate in Africa. In addition, the materials from China were also generally separated into different eco-geographical environments. However, materials from different ecogeographical environments were clustered together. Two materials (Sau02019 and Sau02020) from Guizhou and 5 materials from Chongqing clustered together because all of these samples were collected from mountains at similar altitudes and eco-geographical environments. The 4 materials from Yunnan and 4 materials from Guizhou clustered together because they are located in the Yunnan-Guizhou Plateau, which has the same eco-geographical environment.

However, this correlation is not applicable to all groups. The 2 materials from Chongq- 
ing clustered with the materials from Sichuan. The 6 materials from Guizhou did not cluster together. Two materials clustered with those from Chongqing, while the remaining 4 materials showed a closer genetic relationship with those from Yunnan. There are 3 explanations for this phenomenon. First, the materials were collected from different regions of same province at different altitudes and from different eco-geographical environments. This may account for the variations in the genotypes of materials from the same province. Second, bermudagrass uses a mixed-mating breeding system, which is dominated by asexual reproduction. Human activities and scouring of flood may have led to expanded reproduction in different regions. Third, genetic mutation has occurred throughout evolution of the species, and the mutants may be well-adapted to local natural environment. Therefore, appropriate measures must be used when isolating $C$. dactylon materials from different regions to avoid causing the variation in species because of hybrid populations.

\section{Conservation implications}

It is critical to recognize the genetic diversity and variation among and within accessions to choose relevant strategies for conservation and sampling management. Our analysis of the genetic diversity using the AFLP method may play an important role in protection plans and breeding of new $C$. dactylon var. dactylon varieties. Wild $C$. dactylon var. dactylon is abundant in China. However, because of its strong agamogenesis ability and rapid growth, C. dactylon var. dactylon genetic diversity has been reduced by human activity and flooding in recent years. Our results demonstrated that the AFLP method is a rapid and effective tool for resolving genetic polymorphisms in $C$. dactylon var. dactylon. Our results will be useful for establishing a germplasm resources center, identifying different lines, and breeding new cultivars of $C$. dactylon var. dactylon.

\section{ACKNOWLEDGMENTS}

Research supported by the National Basic Research Program ("973” Program) in China (\#2014CB138705), and the earmarked fund for Modern Agro-industry Technology Research System (\#CARS-35-05). We are thankful to Dr. Bo Xie for his comments and help with the manuscript.

\section{REFERENCES}

Bai GH, Ayele ML, Tefera HL and Nguyen HT (1999). Amplified fragment length polymorphism analysis of tef [Eragrostis tef(Zucc.) Trotter]. Crop Sci. 39: 819-824.

Burton GW (1965). Breeding better bermudagrass. In: Proc. IX Intl. Grassl. Congr., São Paulo, 93-96.

Caetano-Anollés G (1998). DNA analysis of turfgrass genetic diversity. Crop Sci. 38: 1415-1424.

Caetano-Anollés G, Callahan LM, Williams PE, Weaver KR, et al. (1995). DNA amplification fingerprinting analysis of bermudagrass (Cynodon): genetic relationships between species and interspecific crosses. Theor. Appl. Genet. 91: 228-235.

Caetano-Anollés G, Callahan LM and Gresshoff PM (1997). The origin of bermudagrass (Cynodon) off-types inferred by DNA amplification fingerprinting. Crop Sci. 37: 81-87.

Huo J, Yang G, Zhang Y and Li F (2013). A new strategy for identification of currant (Ribes nigrum L.) cultivars using RAPD markers. Genet. Mol. Res. 12: 2056-2067.

Iqbal MA, Sadaqat HA and Khan IA (2008). Estimation of genetic diversity among sunflower genotypes through random amplified polymorphic DNA analysis. Genet. Mol. Res. 7: 1408-1413. 
Karaca M, Saha S, Zipf A, Jenkins JN, et al. (2002). Genetic diversity among forage bermudagrass (spp.). Crop Sci. 42: 2118-2127.

Langdon RFN (1954). The origin and distribution of Cynodon dactylon (L.) Pers. University of Queensland Press, Brisbane.

Liu W (2007). Genetic diversity of bermudagrass accessions in south-west China by ISSRs molecular markers and geographic provenance. Acta Pratacul. Turae. Sinica 16: 55-61.

Liu W (2008). Genetic diversity of Cynodon dactylon accessions based on RAMP markers in Hengduan Mountains from Southwest of China. Seed 27: 56-59.

Mian MA, Hopkins AA and Zwonitzer JC (2002). Determination of genetic diversity in tall fescue with AFLP markers. Crop Sci. 42: 944-950.

Miller MP (1999). Computer note. MANTEL-STRUCT: a program for the detection of population structure via Mantel tests. J. Hered. 90: 258-259.

Nei M and Li WH (1979). Mathematical model for studying genetic variation in terms of restriction endonucleases. Proc. Natl. Acad. Sci. U. S. A. 76: 5269-5273.

Richardson WL, Taliaferro CM and Abring RM (1978). Fertility of eight bermudagrass clones and open-pollinated progeny from them. Crop Sci. 18: 332-334.

Vos P, Hogers R, Bleeker M, Reijans M, et al. (1995). AFLP: a new technique for DNA fingerprinting. Nucleic Acids Res. 23: 4407-4414.

Wilson BL, Kitzmiller J, Rolle W and Hipkins VD (2001). Isozyme variation and its environmental correlates in Elymus glaucus from the California Floristic Province. Can. J. Bot. 79: 139-153.

Wu YQ, Taliaferro CM, Bai GH and Anderson MP (2005). Genetic diversity of burtt-davy and Its relatedness to Hexaploid (L.) Pers. as indicated by AFLP markers. Crop Sci. 45: 848-853.

Wu YQ, Taliaferro CM, Bai GH, Martin DL, et al. (2006). Genetic analyses of Chinese accessions by flow cytometry and AFLP markers. Crop Sci. 46: 917-926.

Yi YJ, Zhang XQ, Huang LK, Ling Y, et al. (2008). Genetic diversity of wild Cynodon dactylon germplasm detected by SRAP markers. Yi Chuan 30: 94-100.

Zhang GF, Guan JM, Lai XP, Lin J, et al. (2011). RAPD fingerprint construction and genetic similarity of Mesona chinensis (Lamiaceae) in China. Genet. Mol. Res. 11: 3649-3657.

Zhang LH, Ozias-Akins P, Kochert G, Kresovich S, et al. (1999). Differentiation of bermudagrass (Cynodon spp.) genotypes by AFLP analyses. Theor. Appl. Genet. 98: 895-902.

Zhang XA, Zhang XQ, Yang CH, Liu W, et al. (2003). General conditions of bermudagrass germ resources and inheritance diversity. Grassland Turf. 4: 3-6.

Zhang YC, Kuang M, Yang WH, Xu HX, et al. (2013). Construction of a primary DNA fingerprint database for cotton cultivars. Theor. Appl. Genet. 12: 1897-1906. 